\title{
periferio
}

\section{INVESTIGACIÓN-FORMACIÓN EN LA CIBERCULTURA: UNA EXPERIENCIA CON RELATOS DIGITALES ${ }^{1}$}

\author{
Tania Lucía Maddalena ${ }^{2}$ \\ Universidade do Estado do Rio de Janeiro \\ Edméa Santos ${ }^{3}$ \\ Universidade do Estado do Rio de Janeiro
}

\section{Resumen}

El presente trabajo presenta una investigación realizada en la Universidad Estatal de Río de Janeiro/Brasil, UERJ, en la disciplina Tecnología Educativa del curso de Pedagogía durante el año 2015, donde se realizaron diversos proyectos que abordaron la creación de relatos digitales como propuesta pedagógica en la formación de futuros docentes. Se utilizaron las bases de la investigación-formación como metodología de investigación, que promueven una inmersión activa y participativa en el campo, formándose en el intercambio con los sujetos de la investigación. Durante un semestre se realizaron tres proyectos con diferentes géneros de relatos digitales: Visual Storytelling en la red social Instagram, Digital Storytelling en formato de vídeo y el blog como memorial hipertextual de formación, las tres propuestas potenciaron la autoría con tecnologías digitales y como resultados obtuvimos producciones innovadoras con narrativas digitales sobre el proceso de formación docente.

Palavras-chave: relato digital; formación docente; investigación-formación

\footnotetext{
${ }^{1}$ El presente artículo fue presentado como comunicación oral en el XIX Congreso Internacional EDUTEC 2016, en la Universidad de Alicante, España.

2 Es estudiante del Doctorado en Educación en el Proped-UERJ. Becaria de investigación doctoral de la agencia CAPES/Brasil. Miembro del GPDOC-UERJ. Magíster en Educación por la UNICAMP. Especialista en Educación y Nuevas Tecnologías de la FLACSO-Argentina, Lic. en Ciencias de la Educación de la UNLP-Argentina. tlmaddalena@gmail.com.

3 Profesora Adjunta de la Facultad de Educación de la UERJ y del Proped-UERJ. Líder del Grupo de Investigación en Docencia y Cibercultura, GPDOC-UERJ. Doctora y Magíster en Educación por la UFBA-Brasil. Posdoctora por la Universidad Abierta de Portugal-UAB. edmeabaiana@gmail.com.
} 


\title{
periferio
}

\section{RESEARCH-TRAINING IN THE CYBERCULTURE: AN EXPERIENCE WITH DIGITAL STORIES}

\begin{abstract}
The present paper discusses part of a research conducted in 2015 during the Educational Technology discipline of the Pedagogy course offered by the State University of Rio de Janeiro, Brazil. As part of the teacher training programme/curriculum of the discipline, various projects addressing the creation of Digital Storytelling were undertaken. The chosen research methodology was the "Research-training" methodology, which promotes an active and participatory immersion of the researcher in their field of study, and with their research subjects/participants, leading to their own continuous professional development. During one semester three projects with different genres of digital stories were undertaken: Visual Storytelling using the social network Instagram; Digital Storytelling in video format and Blog as an hypertext diary training. The three project proposals empowered authorship with the use of digital technologies and as results innovative productions with digital narratives about the teacher training process were obtained.
\end{abstract}

Keywords: digital storytelling; teaching training; research-training 


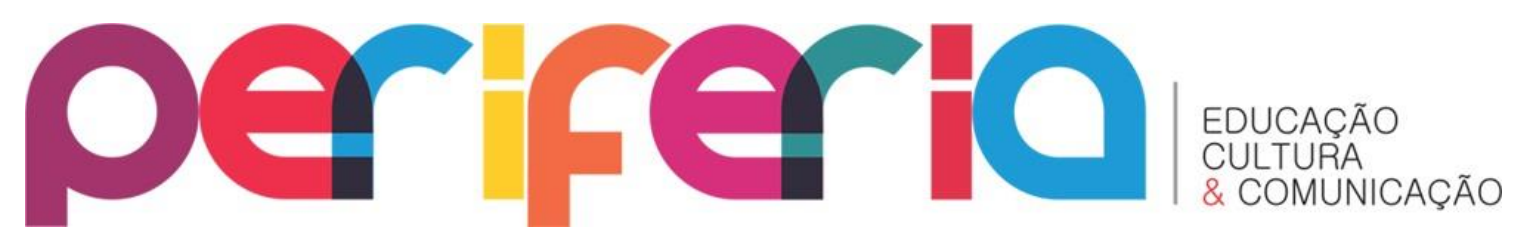

\section{INTRODUCCIÓN}

Los humanos siempre contamos historias. Las contamos durante milenios de forma oral, después a través de las imágenes en las paredes de roca, más adelante por medio de la escritura y hoy mediante todo tipo de pantallas. Más que Homo sapiens somos Homo fabulators. A los humanos nos encanta escuchar, ver o vivir buenos relatos (SCOLARI, 2014, p.17).

Consideramos la cibercultura como nuestro contexto contemporáneo, donde los procesos de enseñanza-aprendizaje se vienen instituyendo. La convergencia de medios y lenguajes, la liberación del polo de emisión, el surgimiento del ordenador conectado, la expansión en el uso de dispositivos móviles, la aparición de las comunidades virtuales de aprendizaje y la utilización de redes sociales son algunas de las características del nuevo escenario socio-técnico. Siendo la cibercultura el contexto actual, partimos de la idea de que no podemos investigar sin una inmersión efectiva en sus prácticas (Santos, 2014).

El arte de contar historias acompaña a la humanidad desde la antigüedad, según Bruner (2014) los seres humanos vivimos inmersos en un mar de historias, estas dan forma y sentido a nuestras experiencias vitales, es en estas historias donde nos relacionamos con otros, establecemos lazos, socializamos y aprendemos. Las narrativas han sido expresadas de diversas formas a lo largo de la historia, en la cibercultura se materializan en una combinación de lenguajes y su difusión puede llegar a lugares antes impensables.

Los relatos digitales surgieron en la década de los 90 en EEUU como pequeños vídeos de 3 a 5 minutos de duración donde el narrador cuenta su historia por medio de la combinación de una variedad de elementos digitales como fotografías, imágenes, música entre otros, siempre con su visión personal sobre el asunto abordado. Creemos que además de este formato audiovisual del relato digital, con la evolución de la web 2.0 y las prácticas de 


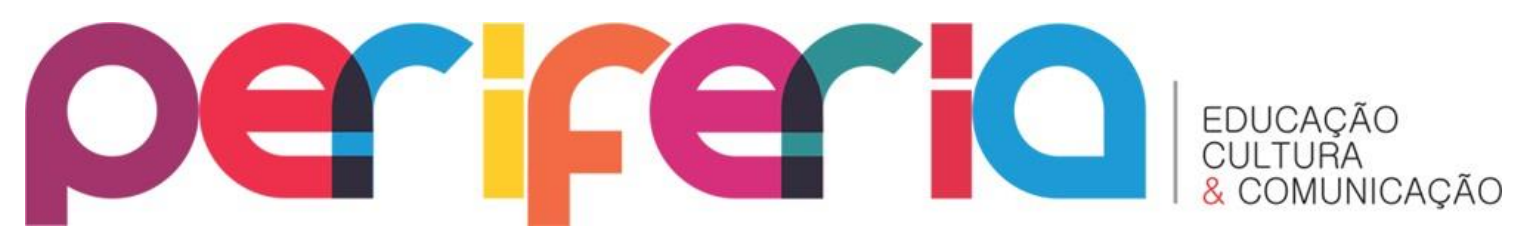

autoría surgen otros géneros de relato digital con el lenguaje hipermedia que proporciona variadas formas de contar historias en la web. Nos inspiramos en estas manifestaciones ciber-culturales para nuestra propuesta de investigación-formación con 40 alumnos del curso de pedagogía, de la disciplina Tecnología Educativa en la Universidad del Estado de Río de Janeiro.

Así, la presente investigación abordó la creación de relatos digitales en la formación de profesores. ¿Cómo los relatos digitales pueden fomentar las autorías docentes con tecnologías digitales? ¿En que medida las narrativas, imágenes y sonidos que configuran los relatos digitales interfieren en la formación de profesores y estimulan su proceso formativo? ¿Cómo se manifiestan las narrativas autobiográficas de los profesores en formación mediante los diversos géneros de relatos digitales?

Para esta propuesta nuestra metodología de investigación utilizó las bases teórico-metodológicas de la investigación-formación multirreferencial, (Santos, 2006; 2014), un abordaje de investigación cualitativa que propone una inmersión en el campo de investigación y entiende que el proceso de investigación se da junto a la práctica pedagógica.

\section{1- EL RELATO DIGITAL COMO GÉNERO HÍBRIDO DEL LENGUAJE HIPERMEDIAL}

La utilización del concepto Digital Storytelling, relato digital, tuvo inicio en la década de los 90 en EEUU, Joe Lambert fue el primer autor en utilizar este término, sus experiencias de investigación con la utilización del relato digital para narrar trayectorias personales a lo largo de muchos años lo hicieron desarrollar la metodología del Digital Storytelling. En 1994, Joe Lambert, Nina Mullen y Dana Atchley fundaron el Storycenter ${ }^{4}$, en Berkeley, California, el centro funciona hasta la actualidad sin fines lucrativos, proporcionando cursos de formación continuada para personas y

\footnotetext{
${ }^{4}$ Storycenter: https://www.storycenter.org/
} 


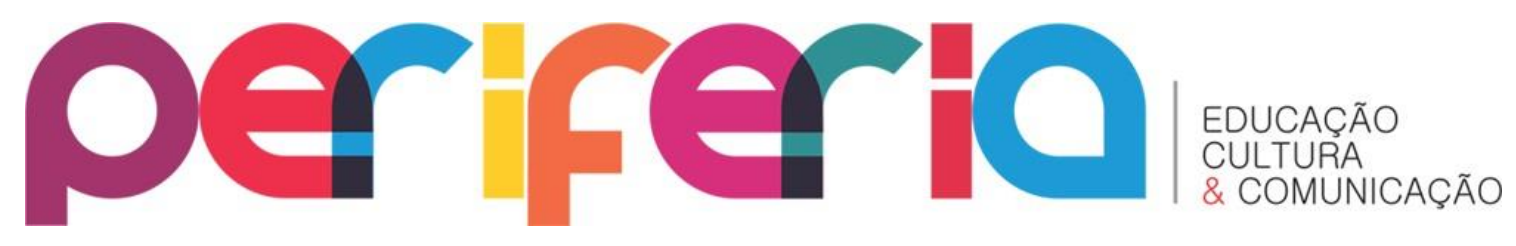

organizaciones que quieran compartir sus historias e iniciarse en las prácticas de creación de historias digitales, promoviendo así cambios individuales y colectivos.

A lo largo de la literatura los relatos digitales han sido definidos como la práctica de combinar el antiguo arte de contar historias con una gran variedad de elementos digitales, siempre hablando desde una perspectiva personal, reconstituyendo vivencias y con reflexiones profundas sobre la temática elegida. Según Lambert (2002) existen siete elementos que deben constituir todo relato digital: el punto de vista, la pregunta dramática, el componente emocional, la voz en off, la banda sonora, la economía narrativa y el ritmo de la narración. Es interesante observar que existe una predominancia del lenguaje audiovisual en esta concepción de Digital Storytelling, el producto final es siempre un vídeo de 3 a 5 minutos de duración. Este vídeo puede estar compuesto por fotografías y diversos materiales que se van combinando y narrando la historia siempre acompañada de la voz del narrador. Los siete elementos de Lambert tuvieron una amplia divulgación en varias esferas del conocimiento y son un marco de referencia para quien desee entrar en el mundo de la creación de relatos digitales.

Creemos que además de este formato audiovisual del relato digital, con la evolución de la web 2.0 y las prácticas de autoría que la misma proporciona surgen otros géneros de relato digital y variadas formas de contar historias en la web. El lenguaje hipermedial está compuesto por diferentes tipos de información (texto, sonido, imágenes, vídeos) que surge a partir de la fusión del hipertexto con los multimedios proporcionado por la digitalización. Todas las informaciones en diversos formatos son transformadas en lenguaje binario y entendidas por todos los procesadores digitales. Así, los soportes analógicos fueron substituidos por las interfaces digitales híbridas donde es posible transitar por medios de variados formatos (multimedios), complementando e intercambiando funciones, esta combinación de lenguaje está fundada por tres fuentes básicas, Santaella (2007) las caracteriza como los signos audibles (sonidos, músicas, ruidos), los signos imagéticos (todas las especies de 


\section{per
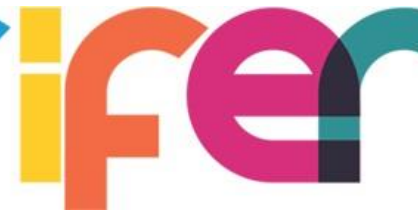

imágenes fijas y animadas) y los signos verbales (orales y escritos) (Santaella, 2007, p.319)

El ciberespacio se apropia de esta combinación, sin ningún límite, todos los lenguajes preexistentes: la narrativa textual, la enciclopedia, los cómics, los dibujos animados, el teatro, el cine, la danza, la arquitectura, el diseño urbano, etc. En este tejido híbrido de lenguajes, nace algo nuevo que, sin perder el vínculo con el pasado, surge con una identidad propia: la multimedia. (SANTAELLA, 2014, p.213)

Según la autora, la multimedia y el hipertexto se funden y dan surgimiento al lenguaje hipermedial. Es este nuevo lenguaje el que se expresa en la web y por medio del mismo surgen nuevos géneros del discurso como: hipervídeos; narrativas transmedia; literatura aumentada; entre otros, que exploran mucho más que el lenguaje verbal. Siguiendo la definición de géneros del lenguaje el propio Bakhtin sostiene:

La riqueza y diversidad de los géneros discursivos es inmensa, porque las posibilidades de la actividad humana son inagotables y porque en cada esfera de la praxis existe todo un repertorio de géneros discursivos que se diferencia y crece a medida de que se desarrolla y se complica la esfera misma". (BAKHTIN, 2006, p. 261)

En esta diversidad de los géneros del discurso que el propio autor clasifica en 1)- géneros discursivos primarios, aquellos que están presentes en el uso cotidiano de la lengua, en la comunicación verbal del día a día, en la oralidad; y 2) géneros discursivos secundarios (como romances, géneros periodísticos, ensayos filosóficos, etc.) son que los aparecen en la comunicación cultural de circunstancias más complejas, con la utilización de lenguajes, como la escritura, por ejemplo. Estas clasificaciones de géneros no son propuestas independientes, al contrario, son complementarias.

M. Bakhtin comprende que durante el proceso de formación de los géneros secundarios, estos pasan a incorporar y transformar los géneros primarios. Este movimiento y relación entre géneros primarios y secundarios 


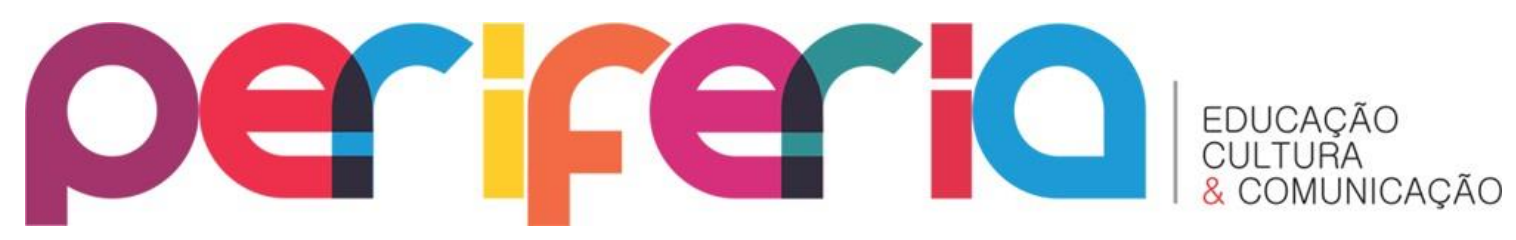

del discurso permite la explicación del principio dialógico del lenguaje, ya que los géneros no son dados de la misma manera que nos es dada una lengua materna, la cual adquirimos mediante enunciados concretos que escuchamos y reproducimos durante la comunicación verbal junto a los individuos que nos rodean. Los géneros se vuelven más complejos en las prácticas cotidianas del lenguaje y se convierten en instrumentos de construcciones nuevas, más complejas. $Y$ es por medio de ellos que organizamos ideas, medios y recursos expresivos en nuestra cultura, garantizando la comunicabilidad de los productos y la continuidad junto a comunidades futuras (MACHADO, 1999).

Según Arlindo Machado (1999, p.143) es en la teoría dialógica de Bakthin que el estudio de los géneros encontró un excelente recurso para radiografiar el hibridismo de los medios y la pluralidad de sistemas de signos de la cultura. Podemos observar que los géneros discursivos forman parte de la dinámica cultural y están en constante transformación, conviviendo a lo largo de la historia en un movimiento de estabilización y recreación. Por esta razón, la riqueza y variedad de géneros es ilimitada. Esta afirmación nos lleva a incorporar la noción de géneros híbridos de Lucia Santaella (2014), que inspirada en la visión bakhtiniana pretende ampliar y crear un nuevo concepto para comprender los fenómenos y prácticas del lenguaje que suceden en la cibercultura.

\begin{abstract}
Ampliar la noción de géneros discursivos para las manifestaciones que ocurren en las redes sociales digitales, bautizando este género de híbrido, dado el hecho de que, en las redes, la discursividad estrictamente verbal sobrepasa las fronteras no solamente de la linealidad típica del verbo, en el hipertexto, sino que también de la exclusividad del discurso verbal en las mezclas que este establece con todas las formas de imágenes fijas y en movimiento y con los lenguajes sonoros, del ruido, a la oralidad y la música, en la multimedia. (SANTAELLA, 2014, p.208) (Traducción de las autoras)
\end{abstract}

Este entendimiento fue de gran importancia en nuestra investigación, ya que las maneras de narrar y contar historias toman nuevas materialidades y 


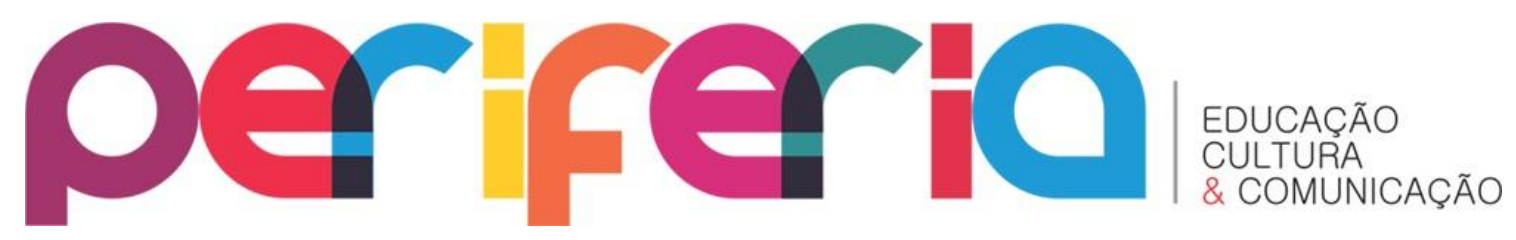

formas en el movimiento de la propia contemporaneidad, consideramos así, los relatos digitales como géneros híbridos del lenguaje hipermedial.

\section{2- PRÁCTICA, EXPERIENCIA Y FORMACIÓN DOCENTE EN LA CIBERCULTURA}

En sus trabajos, Antonio Nóvoa destaca la importancia de la práctica docente como fundadora del proceso de formación y profesionalización docente. Defiende la idea ya utilizada por Paulo Freire en sus diversas obras de que los docentes y discentes aprenden juntos, formando y formándose en el contexto socio-histórico, cultural y ecológico, en el cual la relación profesor-alumno se instituye. Este proceso de aprendizaje incluye dimensiones personales y comunitarias que operan con el concepto de espacio formativo más allá de los límites del espacio geográfico. Según Nóvoa:

El formador se forma a sí mismo, a través de una reflexión sobre sus recursos personales y profesionales (autoformación); el formador se forma en la relación con los otros, en un aprendizaje conjunto que apela a la conciencia, a los sentimientos y a las emociones (heteroformación); el formador se forma a través de las cosas (de los saberes, de las técnicas, de las culturas, de las artes, de las tecnologías) y de su comprensión crítica (ecoformación). (NÓVOA, 2004, p. 16)

Nóvoa destaca la importancia del contexto, de la cultura y sus artefactos y de la complejidad que recae en el concepto de conocimiento. Según Santos (2014) cada vez más los saberes de la experiencia son valorados y destacados en la teoría contemporánea sobre la formación de profesores, en nuestra perspectiva de investigación-formación en la cibercultura esta valorización no es menor, ya que nuestros alumnos, profesores en formación, viven y transitan por diversas prácticas culturales con tecnologías digitales en sus cotidianos, es de suma importancia tener estas prácticas pedagógicas en cuenta a la hora de pensarlas en la formación docente. 


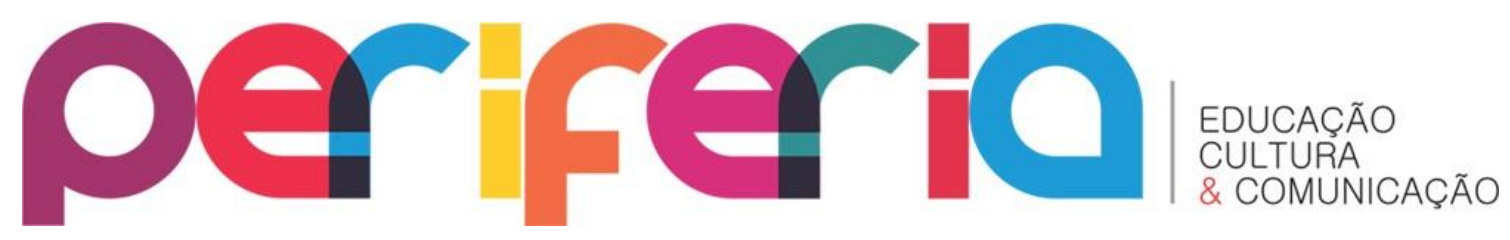

La autora Marie-Cristine Josso (2004), que tiene un gran bagaje en trabajos sobre historias de vida y de formación, destaca el abordaje experiencial fundamentado en tres modalidades sobre la experiencia docente: 1) tener experiencias; 2) hacer experiencias; y 3) pensar sobre las experiencias. La primera nos explica acerca de los saberes, vivencias, experiencias significativas no provocadas por el docente; la segunda se refiere a las vivencias y saberes provocados por los docentes; y la tercera tiene que ver con las vivencias y saberes intencionalmente provocados y repetidos por los docentes como experiencia. Para esta autora tener un proceso reflexivo, de toma de conciencia sobre el proceso de formación es fundamental.

Aquí la narrativa, en sus diversas manifestaciones, va a tomar una importancia central, el ejercicio de narrar acontecimientos y vivencias, articulando en la formación de espacios y tiempos que integran la historia de vida con la historia profesional, basados en experiencias que pueden promover la concientización de las prácticas educativas más reflexivas y el proceso de formación, en el cual es sujeto no es responsable por su formación, sino que también contribuye para la formación de sus pares. En este proceso, el intercambio de subjetividades puede constituirse en un dispositivo fecundo (Santos, 2014).

La principal razón para el uso de la narrativa en la investigación educativa es que los seres humanos somos organismos contadores de historias, organismos que, individual y socialmente, vivimos vidas relatadas. El estudio de la narrativa, por lo tanto, es el estudio de la forma en que los seres humanos experimentamos el mundo. (CONNELLY; CLANDININ, 1995, p.11)

Las narrativas autobiográficas expresan la escritura de "la propia vida" caracterizándose como opuestas a la biografía, ya que el sujeto se traslada para un análisis entre el papel vivido como actor y autor de sus propias experiencias, sin mediación externa de otros (SOUZA, 2006). 


\section{periferio}

Comprender las experiencias formadoras y de aprendizaje experiencial como dimensión del trabajo con el abordaje experiencial o autobiográfico, nos permite acceder a las narrativas autobiográficas de la historia de vida, por entender que la fecundidad de tal opción posibilita aprender desde otro lugar los aprendizajes que fueron construidos a lo largo de la vida y potenciarlos en el transcurso de la formación. (SOUZA; 2006, p.136)

Así, los recuerdos y memorias que forman parte de la formación personal y la historia de vida se manifiestan como fuentes fundamentales en la construcción de saberes de la docencia. En diversos espacios en línea vemos como estas prácticas de "recordar" son estimuladas, la propia red social Facebook trae en la biografía de sus usuarios, memorias y recuerdos de años pasados. Todas estas prácticas ciberculturales se tuvieron en cuenta a la hora de entrar en nuestro campo de investigación-formación.

Nuestro propósito principal fue realizar una investigación-formación que fomente las narrativas autobiográficas de los estudiantes por medio de las tecnologías digitales con la elaboración de los relatos digitales, entendemos como narrativas autobiográficas a las narrativas, imágenes y sonidos que traen momentos, experiencias y reflexiones sobre la vida personal de los propios alumnos y que interfieren en su formación profesional como futuros docentes. Con las bases de la investigación-formación nos propusimos desarrollar tres proyectos que abordaron diversos géneros híbridos de relatos digitales y fomentaron el surgimiento de las narrativas de formación.

\section{3- INVESTIGACIÓN-FORMACIÓN EN LA CIBERCULTURA}

Allí, donde la mayor parte de las otras ciencias son bien sucedidas en perfeccionar, en simplificar los datos de la experiencia a través de recortes apropiados para construir hechos, aquí son siempre prácticas, acontecimientos, situaciones y testimonios, llenos de representaciones, de intenciones $y$ de acciones individuales y colectivas, que construirán la materia rica y diversificada a la cual el 


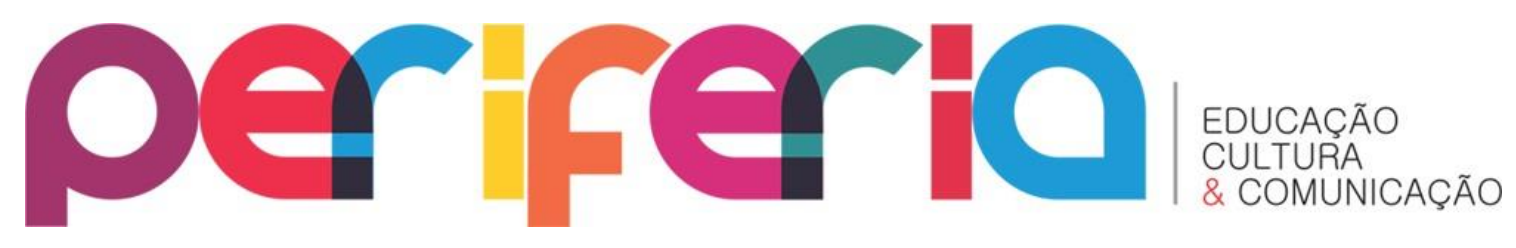

investigador especializado, como actor profano, solamente podrá incansablemente referirse. (ARDOINO, 1998, p.48)

Partimos de la idea de que investigar en la cibercultura es actuar como practicante cultural produciendo datos en red. Los sujetos no son meros informantes, son practicantes culturales que producen culturas, saberes y conocimientos en el contexto de la investigación. Realizar una investigación en la cibercultura no es, para nosotros, solamente utilizar softwares para “colectar y organizar datos”, por eso la investigación-formación está articulada y se desarrolla en el contexto de la docencia. (Santos, 2014). En este sentido, la autoría de la investigación debe ser compartida por todos los participantes del proyecto: profesores-investigadores formadores e investigadores-estudiantes.

Es importante aclarar que el investigador no es considerado un sujeto neutro, descomprometido, que ve a los otros sujetos como seres “investigados", por esta razón la práctica docente se considerada también una práctica de investigación. Esta idea no es nueva en el medio académico, son varios los trabajos que anunciaron y vienen anunciando que enseñar es mucho más que transmitir informaciones sistemáticas y construir situaciones instruccionales que orienten procesos de enseñanza y aprendizaje. Freire (1996) ya afirmaba que enseñar es ser epistemológicamente curioso, esto implica la participación en la construcción del conocimiento del objeto.

En este sentido, el profesor investigador es sobre todo, aquel que aprende mientras enseña y que enseña mientras aprende. Ser epistemológicamente curioso implica tener la capacidad de aprender, "de la cual deriva la de enseñar, y más que eso, implica nuestra habilidad de aprender la substantividad del objeto aprendido". Aprender es “construir, reconstruir, constatar para cambiar, lo que no se hace sin una abertura al riesgo y a la aventura del espíritu” (FREIRE, 1996, p.77).

Así, la investigación-formación en la cibercultura entiende la práctica docente más allá de la racionalidad técnica, las prácticas formativas se 


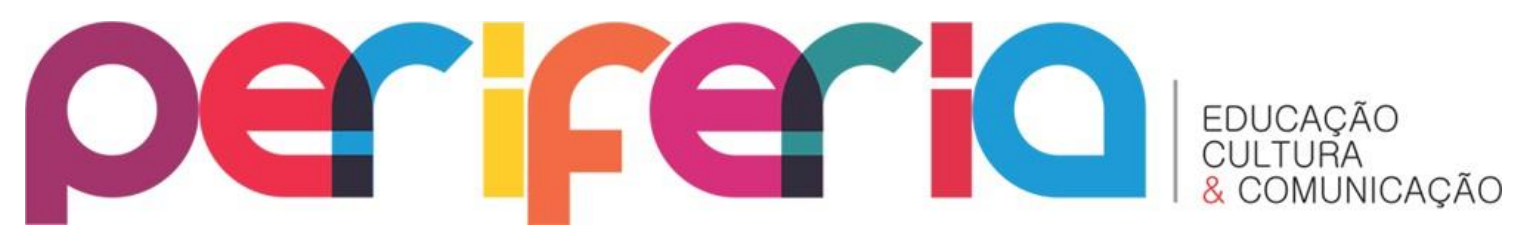

articulan en diversos espacios y tiempos del propio movimiento de las redes, de la movilidad y la ubicuidad de los dispositivos móviles, de las experiencias de lectura y escritura en la hipermedia. Prácticas que cambian, que innovan y que inspiran nuevas prácticas, esta es la dinámica que caracteriza nuestro tiempo. Y con este desafío lidiamos en el cotidiano de nuestro campo de investigación, haciendo y pensando prácticas formativas en red, lo que implica una verdadera inmersión y utilización de las tecnologías digitales como artefactos culturales de dichas prácticas.

Según Santos (2006) "No es posible crear, investigar, o enseñar una experiencia educativa en los principios de la cibercultura e investigaciónformación sin el uso de las interfaces comunicacionales de las TIC como dispositivos de esta formación (SANTOS, 2006, p.124). Las interfaces digitales permiten movilizar una pluralidad de registros y variados géneros de discursos, por esta razón el ambiente virtual se crea a partir de una propuesta pedagógica y de una investigación inicial que se modifica ganando nuevos contornos a lo largo del desarrollo de la investigación-formación. Pensamos la educación en línea no como una mera evolución de las prácticas masivas de educación a distancia, sino como un fenómeno de nuestro tiempo, de nuestra cultura contemporánea que entiende que los sujetos se forman en movimiento, sin separar los contextos educativos de las ciudades y sus artefactos culturales. Por esta razón buscamos inspiraciones formativas que provienen de la cultura, que llevamos a nuestras prácticas en las clases y utilizamos diversas plataformas digitales como espacios multirreferenciales de aprendizaje.

Partiendo de estos fundamentos, en las prácticas de una investigaciónformación se crean diversos dispositivos formativos, pensados como actos curriculares, que generan conocimientos y reestructuran la práctica, estos dispositivos son en realidad tácticas (Certeau, 2013) singulares que los sujetos realizan para lidiar con los dilemas vivenciados en su docencia. Los tres proyectos abordados en este artículo muestran tres tipos de dispositivos formativos inspirados en los géneros híbridos de los relatos digitales. 


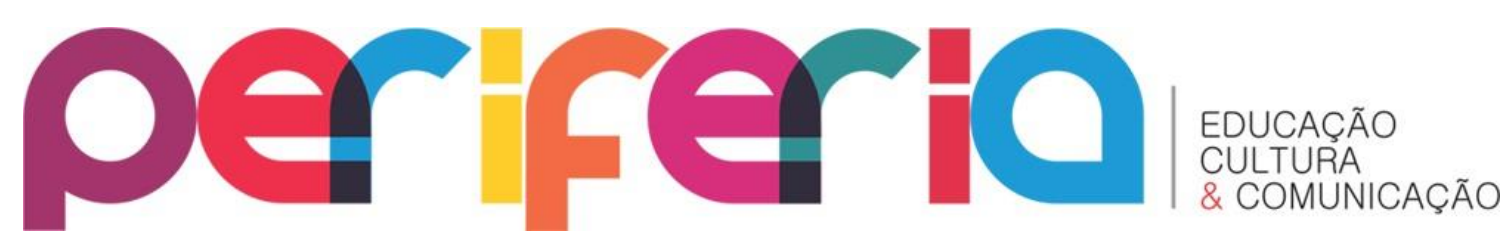

Finalmente, todos los datos que surgen del campo de la investigaciónformación se materializan en narrativas e imágenes, el estudio de las narrativas del proceso de formación docente toman un lugar central en este abordaje, por eso mismo es una opción metodológica traer a nuestros sujetos practicantes con sus verdaderas identidades ${ }^{5}$.

\subsection{CAMPO, PRACTICANTES Y DISPOSITIVOS DE LA INVESTIGACIÓN- FORMACIÓN}

El campo de la presente investigación-formación fue realizado en la Universidad Estatal de Río de Janeiro (UERJ), en la disciplina Tecnología Educativa del curso de Pedagogía. Durante el segundo semestre del 2015 un grupo de 40 alumnos participaron de la disciplina y de los tres proyectos que abordaron diferentes géneros de relatos digitales.

Cabe mencionar que la UERJ es una de las universidades públicas de excelencia con mayor índice de población periférica en Río de Janeiro, muchos de nuestros alumnos, futuros docentes, provienen de barrios alejados y viajan durante horas para llegar al curso de formación. La disciplina Tecnología Educativa es una disciplina obligatoria del primer semestre de la carrera de Pedagogía, entonces muchos llegaron a nuestras clases sin conocer a sus compañeros ni las historias que cada uno traía consigo. Nuestra propuesta parte de este contexto, las narrativas de cada alumno fueron incentivadas desde nuestra propuesta pedagógica donde articulamos diversos dispositivos de investigación.

El primer día de clase creamos un grupo de la disciplina en la red social Facebook, ya que entendemos a nuestros alumnos como practicantes culturales que viven la cibercultura en su cotidiano y Facebook es una red que habitan, por esta razón elegimos crear un grupo allí para extender nuestro intercambio de la clase presencial y poder potenciar las autorías en red. Este

\footnotetext{
${ }^{5}$ Todos los sujetos practicantes de la investigación-formación citados en el presente artículo autorizaron la divulgación de imágenes, vídeos, blogs y autorías realizadas durante la disciplina Tecnología Educacional.
} 


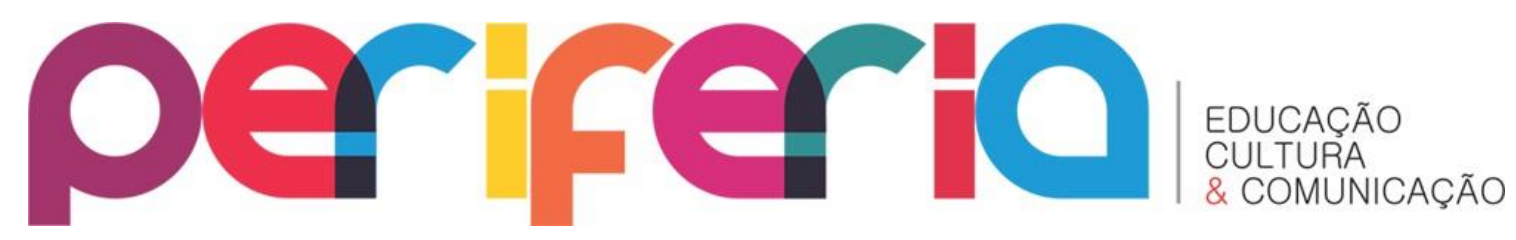

grupo no tuvo la intención de resolver cuestiones administrativas, fue un dispositivo de la investigación-formación que funcionó como un espacio fructífero de intercambios sobre el contenido de la disciplina. Compartimos vídeos, textos, páginas webs, los propios alumnos trajeron diversas cuestiones que proporcionaron discusiones, debates y sin duda, aprendizajes.

Durante el semestre fueron desarrollados tres proyectos, entendidos como dispositivos de la investigación-formación, que abordaron diversos géneros de relatos digitales: Visual Storytelling en Instagram; Digital Storytelling en formato de vídeo; Blog como memorial hipertextual de formación, a continuación describiremos los proyectos y presentaremos algunas imágenes y narrativas resultantes del proceso creativo.

\section{4- HISTÓRIAS, IMÁGENES Y NARRATIVAS DIGITALES DE FORMACIÓN}

El primer proyecto Visual Storytelling en Instagram buscó trabajar la memoria escolar de nuestros alumnos, futuros docentes. Nuestra propuesta fue que traigan fotografías de su infancia en la escuela y que narren sus memorias de aquella época. El ejercicio de recordar cambió el ambiente de nuestra clase, comenzamos la actividad oralmente y después pedimos para que todos instalen el App Instagram en sus dispositivos móviles, para nuestra sorpresa todos los alumnos ya eran usuarios de la red social entonces pasamos directamente a nuestra actividad. Sacaron fotos y las editaron en la red social, en la parte de la descripción de la imagen narraron una historia que de alguna manera refiriese o se asociase a la imagen. No fue meramente un proceso de digitalización de la imagen, consideramos al Visual Storytelling un fenómeno de la cibercultura donde la imagen, el texto, los hashtags y la localización se componen como un todo. 


\section{periferio}

Figura 1 - Proyecto Visual Storytelling y memória escolar en la red social Instagram

\#digitalstorytellinguerj

30 publicaciones

PUBLICACIONES DESTACADAS
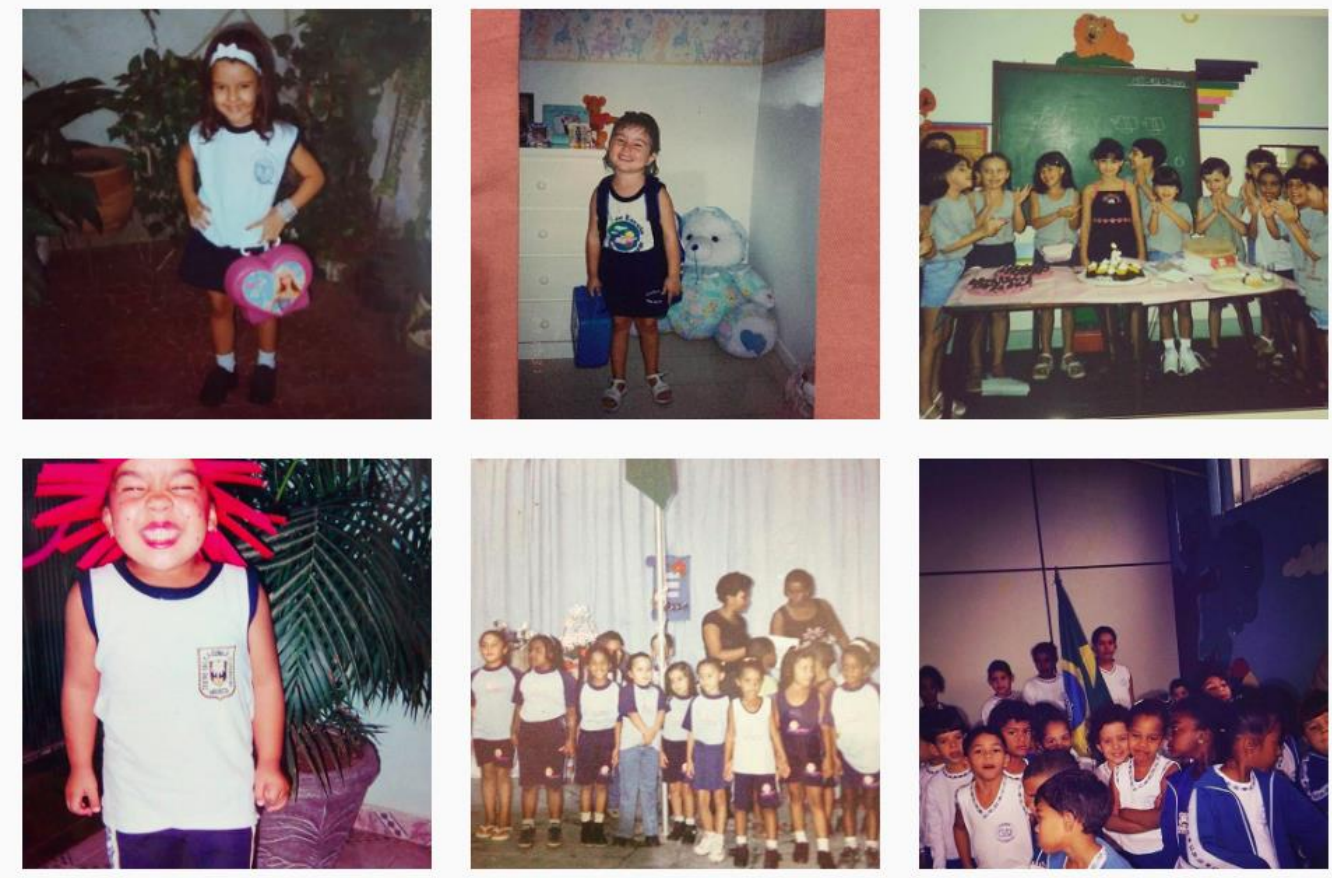

Fuente: acervo de las autoras, 2017.

Por medio del hashtag \#DigitalStorytellingUERJ vimos los trabajos de todos los alumnos, el hashtag funcionó como nexo conector y hasta la actualidad pueden observarse estos registros en la red social. Es importante mencionar que además del ejercicio de narrativa escolar de cada alumno, esta actividad fomentó el intercambio con las historias de todos los alumnos de la clase, no solo en la clase presencial sino también y sobre todo en la red social, ya que la posibilidad de realizar comentarios en cada Visual Storytelling se dió de manera muy rápida. 


\section{periferio}

Figura 2 - Visual Storytelling en la red social Instagram.

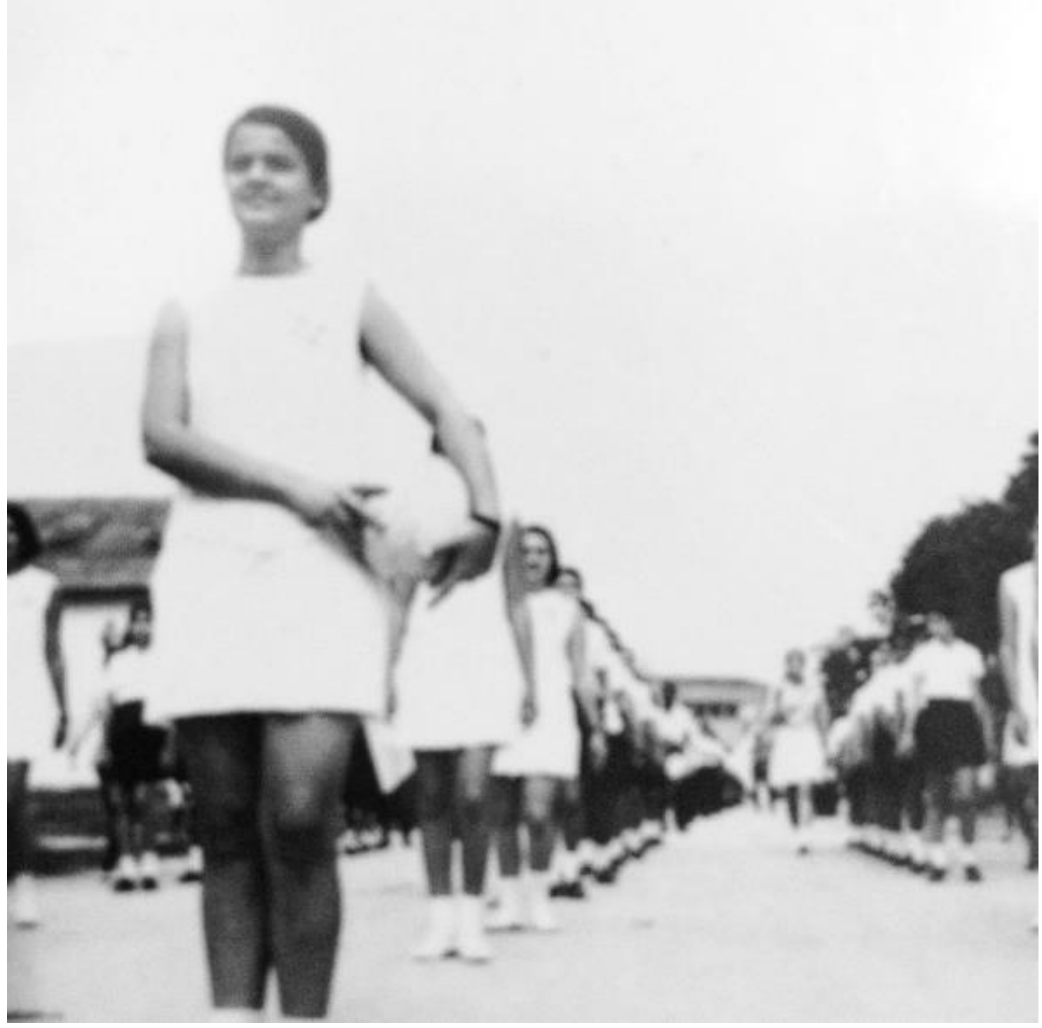

a.7) lucia.reginaas

lucia.reginaas Estudei no Grupo Escolar Capitão Godoi, em Minas. Como a cidade é pequena, as famílias compartilhavam a vida escolar e social. Nossos pais também eram amigos. Era um tempo muito bom! Este foi um desfile de sete de setembro. Eu participava todo ano e meus pais tinham muito orgulho por isso. Toda a cidade se reunia durante a comemoração. Havia o desfile, uma banda de música, festa na escola! \#digitalstorytellinguerj

lorenamrll Linda foto!! (9) luiizaalopees Arrasou $=$ mariisatorres_Lindaaa

raquelmalaq Que fofa! $\bullet$ Você lembra o nome de sua professora?

tanumaddalena Adorei seu relato!! @lucia.reginaas que outras coisas lembra da sua escola? Conta mais, queremos saber!

Añade un comentario...

Fuente: Instagram de la alumna Lucia Regina.

Nuestro segundo proyecto fue la realización de relatos digitales en el formato de vídeo, siguiendo los siete pasos propuestos por Joe Lambert (2002). Para esta propuesta estudiamos los componentes básicos de un guión, trama de una historia, creación de personajes de ficción, desenlace y cierre de la historia, entre otros. Nuestra propuesta disparadora fue ¿Cómo llegó la tecnología digital a mi vida?, los alumnos se dividieron en parejas y tríos para la realización de los vídeos, el proyecto duró aproximadamente un mes y medio que se dividió en tres partes: 1ro- la escritura de la historia, guión, búsqueda de materiales. 2do- el proceso de edición y 3ro- la exposición del vídeo y los comentarios sobre el proceso, esta exposición se realizó en la clase presencial y en nuestro grupo de la disciplina en Facebook. 


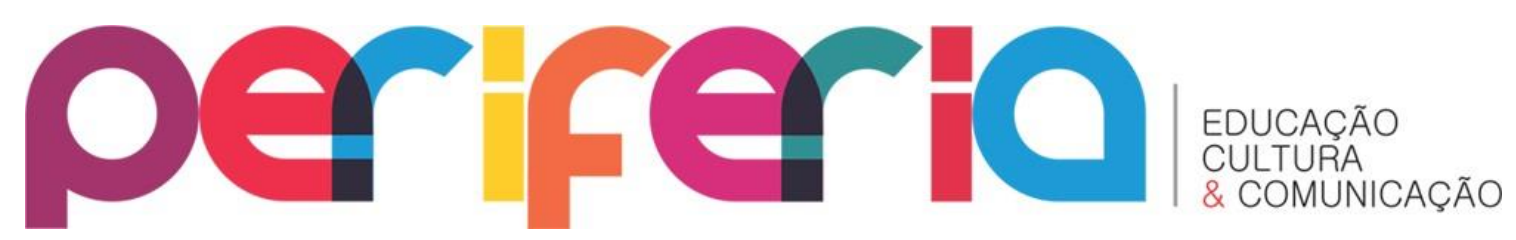

Figura 3 - Digital Storytelling "El avance de la tecnología: historia de Renata". Enlace compartido en el grupo de la disciplina en Facebook.

- Maria Luiza Schuaste com Raphaela Novello e Marisa Torres.

31 de outubro de 2015

Olá turma!!! Finalmente consegui subir o vídeo para o youtube.Foi a minha maior dificuldade, pois a internet não ajudou muito.Foi criado,produzido $e$ editado com muito carinho espero q gostem!! A escolha da música foi proposital, a música feel so clone do Calvin harris em tradução livre significa: Eu me sinto tão perto de você agora. Essa frase traduz um pouco o que a tecnologia faz,Afinal com ela todos ficamos "perto"

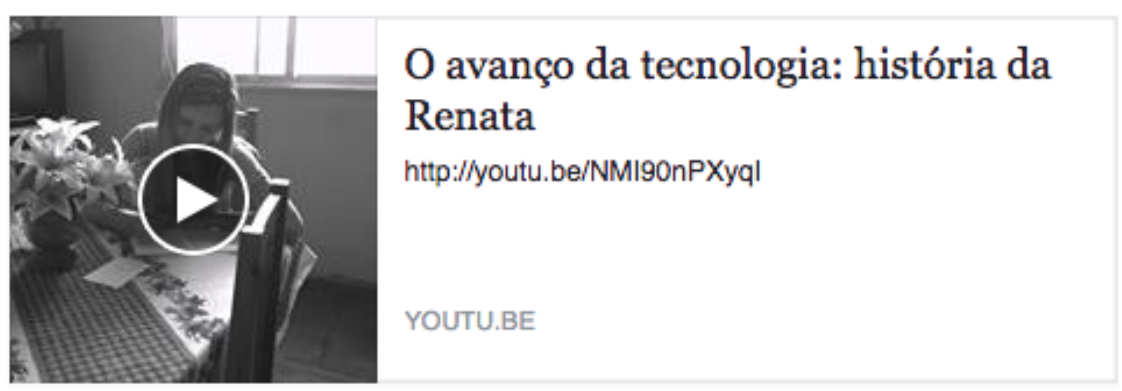

It Curtir $\quad \Rightarrow$ Comentar Compartillhar

(1) Você, Edmea Santos, Alice Costa e outras 13 pessoas $\quad \checkmark$ Visualizado por 59

Ver mais 10 comentários

7 Alice Costa Olá Maria Luiza Schuaste, Raphaela Novello e Marisa Torres, a digital storytelling de vocês ficou muito bacana!

Curtir - Responder - $\mathbb{B} 2 \cdot 16$ de novembro de 2015 às 19:11

Lena Chianello Mito boa abordagem, parabéns meninas! show!!!

Curtir - Responder - 1317 de novembro de 2015 às 00:20

Fuente: Grupo de la disciplina Tecnologia Educacional en Facebook

Como último proyecto cada alumno creó un blog como "memorial hipertextual de formación" en el cual se recopilaron todos los trabajos que realizamos en la disciplina Tecnología Educativa, el blog apuntó a que cada alumno pudiese escribir sus propias impresiones sobre la disciplina y el primer año de universidad. Intentado fomentar sus narrativas autobiográficas de manera hipertextual, utilizando vídeos, enlaces, fotografías y todo lo que el lenguaje hipermedial les permitiese en la plataforma elegida para la 


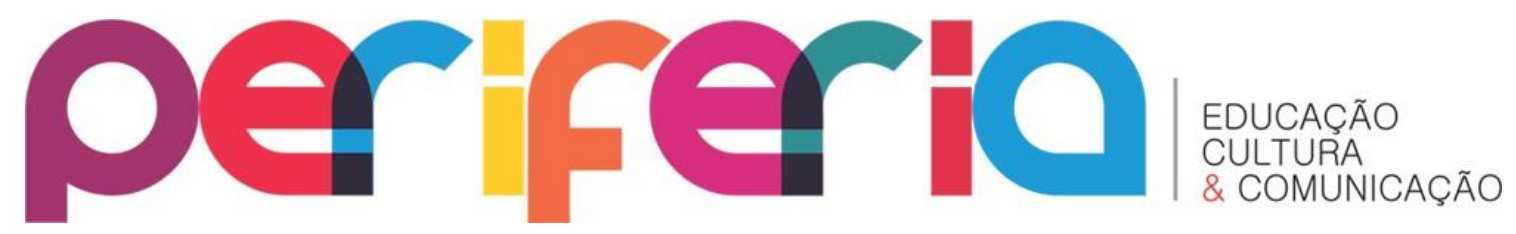

realización del blog. Todos los alumnos de la clase crearon sus blogs y fueron compartiendo los links en nuestro grupo de la disciplina en Facebook.

Figura 4 - Blog como memorial hipertextual de formación

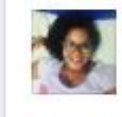

Monique Carvalho

29 de novembro de 2015 . Rio de Janeiro

Boa noite, gente! Nesse primeiro ano de UERJ muita coisa mudou pra mim. Eu entendi que temos que estar atento às constantes influencias ruins que nos cercam, como aquela piada machista, aquele comentário que banaliza a violência contra a mulher, etc. Mas ainda falta MUITA desconstrução, e a isso, dedico meu blog.

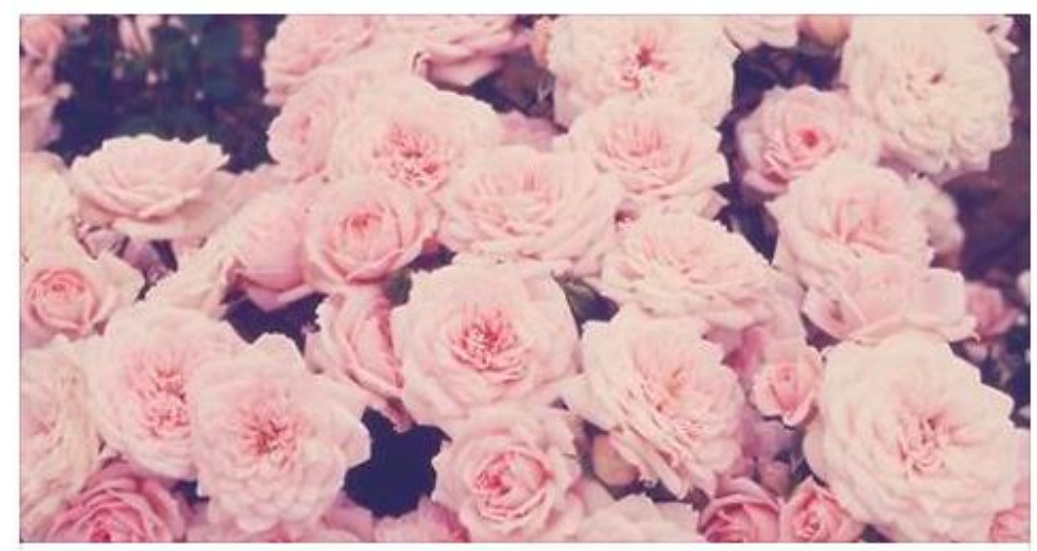

Negra, mulher, brasileira, universitária, professora, aluna.

FOFAREVOLTADA.BLOGSPOT.COM I POR MONIQUE CARVALHO

In Curtir Comentar $\rightarrow$ Compartilhar

(1) Você, Edmea Santos, Hugo Charret e outras 6 pessoas $\quad \checkmark$ Visualizado por 58

Hugo Charret Arrasa néééim :(:)
Curtir - Responder - $31 \cdot 29$ de novembro de 2015 às 11:13
Edmea Santos Yes !
Curtir - Responder - $31 \cdot 29$ de novembro de 2015 às $13: 49$

Fuente: Grupo de la Disciplina Tecnología Educacional en Facebook

\section{ALGUNAS CONSIDERACIONES}

A lo largo de este artículo expusimos los principales delineamentos de nuestra investigación-formación, una experiencia de investigación comprometida con la formación de futuros docentes que se preocupó por 


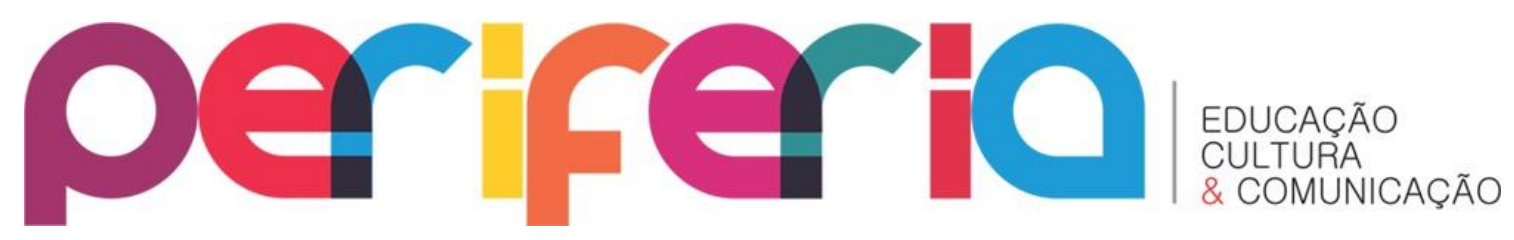

comprender como la creación de relatos digitales puede fomentar el surgimiento de narrativas del proceso de formación, narrativas en formato digital que movilizaron diversas literacies, tanto en la creación con las tecnologías digitales como en su utilización para propuestas pedagógicas.

Fueron tres proyectos específicos que profundizaron diversos aspectos: memoria escolar, la llegada de la tecnología digital y un memorial que abordó todos los aprendizajes y el recorrido de la disciplina. Todos los proyectos tomaron como eje principal las historias de formación y narrativas autobiográficas de nuestros alumnos, profesores en formación. Como resultados obtuvimos autorías creativas, en las cuales se puede observar que en cada proyecto, hasta en la elección por narrar de historias de ficción se expusieron experiencias, momentos y recuerdos de sus propias trayectorias de vida.

Todo este material está disponible en internet, en la red social Instagram el trabajo con Visual Storytelling y memoria escolar, en YouTube todos los relatos digitales sobre la llegada de la tecnología digital en formato de vídeo, y los blogs en las plataformas Blogger y Wordpress.

Como consideración final podemos sostener que narrar, crear y recrear historias digitales implicó un proceso autoral, en el cual la reconstrucción de las narrativas provocó una conciencia sobre el lenguaje hipermedial que habita en las redes que más allá de trabajar con las diversas literacies, situó al narrador (estudiante y profesor) en el aquí y ahora de su experiencia narrada, sin duda todo este proceso fue muy formativo para todos los involucrados en la investigación-formación.

\section{REFERENCIAS}

ARDOINO, J. Abordagem multirreferencial (plural) das situações educativas e formativas. In: BARBOSA, J. Multirreferencialidade nas ciências e na educação. São Carlos: EdUFSCar, 1998. pp. 24- 51.

BAKHTIN, M. Estética da criacão verbal. São Paulo: Martins Fontes, 2006. 


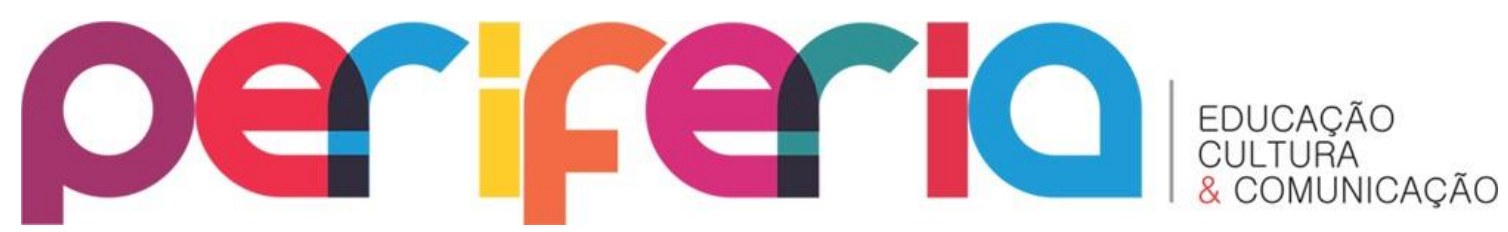

BRUNER, J. Fabricando Histórias: Direito, Literatura, Vida. San Pablo: Letra e Voz, 2014.

CONNELLY, F.; CLANDININ, J. Relatos de Experiencia e Investigación Narrativa. In: LARROSA, J.; ARNAUS, R.; FERRER, V.; PEREZ, N.; CONNELLY, F. M.; CLANDININ, J. D.; GREENE, M. Déjame que te cuente, ensayos sobre narrativa y educación. Barcelona: Editorial Laertes, 1995. p.11-59.

FREIRE, P. Pedagogia da autonomia: saberes necessários à prática educativa. São Paulo: Paz e Terra, 1996.

JOSSO, M. C. Experiências de vida e formação. São Paulo: Cortez, 2004.

LAMBERT, J. Digital Storytelling: capturing lives, crating community. Berkeley: Digital Diner Press, 2002.

MACHADO, A. Pode-se falar em gêneros televisuais?. Revista Famecos, Porto Alegr, N.10, p. 142-158, jun. 1999.

NÓVOA, A. Prefácio. In: JOSSO, M.C. Experiências de vida e formação. São Paulo: Cortez, 2004. p. 11-34.

SANTAELLA, L. Gêneros discursivos híbridos na era da hipermídia.

Bakhtiniana. São Paulo, v. 9, n. 2, p. 206-216, 2014.

SANTOS, E. Pesquisa-formação na cibercultura. Lisboa: Whitebooks, 2014.

SANTOS, E.; ALVES, L. Práticas Pedagógicas e Tecnologias Digitais. Rio de Janeiro: E-papers, 2006.

SOUZA, E. C. de. Pesquisa narrativa e escrita (auto)biográfica: interfaces metodológicas e formativas. In: SOUZA, E. C. de; BARRETO, A. M. Tempos, narrativas e ficções: a invenção de si. Porto Alegre: EDIPUCRS, 2006. p. 135147.

SCOLARI, C. Narrativas Transmedia: Cuando los medios cuentan. Barcelona: Deusto, 2013. 